\title{
ENSINO MÉDIO EM TEMPO INTEGRAL E A ESCOLA DE ANTONIO GRAMSCI
}

\author{
AVERAGE MID-TERM EDUCATION AND THE SCHOOL OF ANTONIO GRAMSCI \\ ENSEÑANZA MEDIO EN TIEMPO INTEGRAL Y LA ESCUELA DE ANTONIO \\ GRAMSCI
}

\author{
Flávia Gonçalves da SILVA ${ }^{1}$ \\ Elisangela da Silva BERNADO²
}

RESUMO: Esse artigo apresenta elementos que compõem o debate atual sobre o Ensino Médio em Tempo Integral, mais especificamente, a política pública intitulada Programa Ensino Médio Inovador criado em 2009 pelo Governo Federal e implementado nos diversos estados da Federação e a escola pensada por Antonio Gramsci. Busca através de aproximações e/ou antagonismos conversar com as ideias deste autor e de outros como Frigotto; Motta (2017), Savianni (2003) que se debruçaram sobre a temática do ensino médio no Brasil. A possibilidade da utilização dos conceitos de Gramsci no desenvolvimento de uma escola de ensino médio mais igualitária fez parte da construção deste estudo. A metodologia utilizada foi a pesquisa qualitativa, apoiada na análise documental e na pesquisa bibliográfica.

PALAVRAS-CHAVE: Ensino médio integral. Políticas públicas. Escola unitária.

RESUMEN: Este artículo presenta elementos que componen el debate actual sobre la Enseñanza Media en Tiempo Integral en Brasil, más específicamente, la política pública titulada Programa Enseñanza Media Innovador creado en 2009 por el Gobierno Federal e implementado en los diversos estados de la Federación y la escuela pensada por Antonio Gramsci. Busca a través de aproximaciones y / o antagonismos conversar con las ideas de este autor y de otros como Frigotto; Motta (2017), Savianni (2003) que se inclinaron sobre la temática de la enseñanza media en Brasil. La posibilidad de la utilización de los conceptos de Gramsci en el desarrollo de una escuela de enseñanza media más igualitaria formó parte de la construcción de este estudio. La metodología utilizada fue la investigación cualitativa, apoyada en el análisis documental y en la investigación bibliográfica.

PALABRAS CLAVE: Enseñanza media integral. Políticas públicas. Escuela unitaria.

\footnotetext{
${ }^{1}$ Universidade Federal do Estado do Rio de Janeiro (UNIRIO), Rio de Janeiro - RJ - Brasil. Mestranda em Educação (PPGEdu). ORCID: <https://orcid.org/0000-0001-5249-3001>. E-mail: flaviagsmendes@gmail.com ${ }^{2}$ Universidade Federal do Estado do Rio de Janeiro (UNIRIO), Rio de Janeiro - RJ - Brasil. Professora Adjunta do Programa de Pós-Graduação em Educação e da Escola de Educação Coordenadora do Mestrado em Educação/PPGEdu - Centro de Ciências Humanas e Sociais - CCH Departamento de Fundamentos da Educaçãolider do Grupo: Líder do Grupo de Pesquisa "Políticas, Gestão e Financiamento em Educação. ORCID: <https://orcid.org/0000-0003-3994-0254>. E-mail: efelisberto@yahoo.com.br
} 
ABSTRACT: This article presents elements that compose the current debate on the Integral High School in Brazil, more specifically, the public policy entitled Teaching Higher Education Program created in 2009 by the Federal Government and implemented in the different states of the Federation and the school designed by Antonio Gramsci. Seeks through approximations and / or antagonisms to talk with the ideas of this author and others like Frigotto; Motta (2017) and Savianni (2003) who focused on the subject of secondary education in Brazil. The possibility of using Gramsci's concepts in the development of a more egalitarian secondary school was part of the construction of this study. The methodology used was qualitative research, supported by documental analysis and bibliographical research.

KEYWORDS: Integral secondary education. Public policies. Unitary school.

\section{Introdução}

A Constituição Federal de 1988 e LDBEN de 1996 foram importantes marcos para a democratização da educação no país. Frutos de muita luta dos diversos movimentos sociais organizados em todo o país. (SAVIANNI, 2016) Mesmo com o entendimento que avanços ocorreram nesta área, foi possível constatar durante este estudo, uma série de leis, decretos, portarias e programas instituídos após a implementação destes marcos que direcionam iniciativas e principalmente recursos de acordo com os interesses de grupos específicos. Pretendemos neste artigo, focalizar alguns instrumentos normativos elaborados pós Constituição Federal de 1988 e LDBEN de 1996 que influenciaram diretamente os rumos do Ensino Médio, como a lei 11.494, de 20 de junho de 2007 que regulamenta o Fundo de Manutenção e Desenvolvimento a Educação Básica e de Valorização dos Profissionais da Educação (FUNDEB), O PARECER CNE/CP N. 11/2009 sobre a Proposta de experiência curricular inovadora do Ensino Médio e a Portaria 971 de 09 de Outubro de 2009 que instituiu o Programa Ensino Médio Inovador (PROEMI), com vistas a apoiar e fortalecer o desenvolvimento de propostas curriculares inovadoras nas escolas do ensino médio não profissional e o Plano Nacional de Educação instituído pela lei $\mathrm{n}^{\circ} 13.005$, de 25 de junho de 2014.

Na parte introdutória do Documento Orientador do Proemi 2009, o Ministério da Educação (MEC) por meio da Secretaria de Educação Básica (SEB), trata da identidade do Ensino Médio e afirma que ela se define na superação do dualismo entre propedêutico e profissionalizante.

Busca-se uma escola que não se limite ao interesse imediato, pragmático e utilitário. $\mathrm{O}$ ensino médio deverá estruturar-se em consonância com o avanço do conhecimento científico e 
tecnológico, fazendo da cultura um componente da formação geral, articulada com o trabalho produtivo. Isso pressupõe a vinculação dos conhecimentos científicos com a prática relacionada à contextualização dos fenômenos físicos, químicos, biológicos e sociais, bem como a superação das dicotomias entre humanismo e tecnologia e entre formação teórica geral e técnica-instrumental (BRASIL, 2009, p. 4).

E mesmo com realidades muito distintas entre a Itália do início do século XX e a luta de Gramsci pelo socialismo em seu país e o Brasil do século XXI, capitalista e cada vez mais comprometido com a preparação dos jovens para a formação para o mercado de trabalho e sendo essa formação vista como um dos fatores de produção (FRIGOTTO; MOTTA, 2017, p. 358), percebemos, mesmo que apenas conceitualmente, uma aproximação entre as ideias que embasaram a criação do Programa Ensino Médio Inovador e a Escola Unitária de Gramsci.

Gramsci recusava a tendência a especialização rígida, entendida como a separação das funções intelectuais, defendia assim uma formação harmônica para os homens. A formação clássica para Gramsci era a formação para todos. E não a enciclopédica reservada às elites. Mas foi com a fundação da revista Ordinue Novo em 1919 que a discussão sobre a necessidade de unificação teórico e prática do ensino se torna mais forte. A crescente industrialização da Itália e a carência de novos profissionais, colocou a carência de repensar os novos modelos educativos, um novo modelo de escola unitária. (META, 2017)

Este artigo está dividido em três seções, além da introdução. Na primeira, discutiremos o papel do Ensino médio, última etapa da Educação Básica e quais as principais políticas desenvolvidas nesta área. Dando ênfase à Política de indução de Educação Integral em tempo Integral chamada Programa Ensino Médio Inovador PROEMI, criada pela Portaria $N^{\circ}$ 971, de 09 de outubro de 2009. E que vem sendo desenvolvida na rede pública dos diversos estados da Federação e que no estado do Rio de Janeiro se uniu a Proposta de Ensino Médio Inovador ampliando o tempo do aluno na escola. Na segunda seção, conversaremos com alguns conceitos desenvolvidos por Antonio Gramsci e utilizados até hoje por muitos educadores como inspiração na construção de uma sociedade igualitária. E na terceira e última parte tecemos algumas considerações de como os conceitos desenvolvidos por Gramsci podem ou não contribuir com uma escola de Ensino Médio Inovadora nos dias atuais.

\section{Ensino Médio e Educação em Tempo Integral: um olhar sobre as políticas públicas e a legislação}


Percebemos como fundamental refletir sobre os diversos ordenamentos jurídicos que visam garantir um direito que deveria ser comum a todos. E sobre a constatação que nas sociedades como a brasileira, onde o capitalismo dependente ${ }^{3}$ combina elevada concentração de riqueza e capital e desigualdade, em nada contribui para que se efetive uma distribuição dos bens sociais de forma justa, esse ordenamento jurídico também é alvo de disputa. E nesse aspecto ousamos trazer uma reflexão em caráter introdutório, de qual é papel do Ensino Médio na sociedade atual e das principais políticas públicas que vêm sendo desenvolvidas para esse segmento da Educação Básica.

Höfling (2001) nos alerta para o fato das políticas públicas se desenvolverem no interior do Estado e ganharem um contorno de acordo com o tipo de Estado e momento histórico de sua implementação. E avança no sentido de diferenciar os conceitos de Estado e de Governo essenciais para o entendimento das políticas públicas. A autora assim define esses conceitos:

Estado como um conjunto de instituições permanentes-como órgãos legislativos, tribunais, exército e outras que não formam um bloco monolítico necessariamente- que possibilitam a ação do governo; e Governo, como o conjunto de programas e projetos que parte da sociedade (políticos, técnicos, organismos da sociedade civil e outros) propõe para a sociedade como um todo, configurando-se a orientação política de um determinado governo que assume e desempenha as funções de Estado por um determinado período (HÖFLING, 2001, p. 31).

A educação é entendida como uma política pública de responsabilidade do Estado, mas não pensada somente por seus organismos (HÖFLING, 2001). Sendo assim, a disputa pelo modo como a sociedade deve se organizar e fazer uso dos recursos públicos e travada no interior das sociedades constantemente.

Shiroma (2000), retrata o cenário politico dos anos de 1990 como essencial para o entendimento das politicas públicas implementadas aqui no Brasil e em diversas partes do mundo, desde então. Cita a Inglaterra no governo Thatcher (1979-1990) como o maior exemplo de mudanças significativas no que se refere as politicas nas diversas áreas, como saúde, educação, liberdade de organização de trabalhadores, dentre outros direitos.

Os conservadores lograram transformações tão extensas e radicais nesse período, que podem se vangloriar de terem efetivado a desregulamentação, a privatização, a flexibilização, o estado mínimo, pontos indisputáveis do que hoje recebe a designação, pouco precisa, mas notável eficácia ideológica, de neoliberalismo (SHIROMA, 2000, p. 53).

${ }^{3}$ Capitalismo dependente; conceito utilizado por Frigotto e Ciavatta (2011) com base nos trabalhos de Marine (2000) e Fernandes (1973). 
A autora pontua os estragos que essas mudanças causaram na Inglaterra, onde a sociedade já havia logrado grandes conquistas da cidadania e já havia o estado de bem-estar social elevado. No Brasil, os estragos foram muito maiores. E pôde ser mais sentido a partir do governo Fernando Collor de Mello, em 1990. Iniciou-se o processo de ajuste da economia brasileira às exigências de reestruturação global da economia. Na Educação a Teoria do Capital Humano, muito utilizada nos anos 70, período de ditadura militar no Brasil estava em alta novamente. A máxima era que o novo paradigma produtivo demandava requisitos de educação geral e qualificação profissional dos trabalhadores. A educação mais uma vez era entendida como a propulsora do desenvolvimento econômico.

Nosso olhar, a partir dessas considerações volta-se para a legislação da Educação na Constituição Federal de 1988, na Lei de Diretrizes e Bases da Educação Nacional de 1996 e nas principais legislações com foco no Ensino Médio após 1988. A Constituição Federal descreve o dever do Estado com a Educação

Art. 208. O dever do Estado com a educação será efetivado mediante a garantia de:

I - educação básica obrigatória e gratuita dos 4 (quatro) aos 17 (dezessete) anos de idade, assegurada inclusive sua oferta gratuita para todos os que a ela não tiveram acesso na idade própria; (Redação dada pela Emenda Constitucional $n^{\circ} 59$, de 2009)

II - progressiva universalização do ensino médio gratuito; (Redação dada pela Emenda Constitucional $n^{\circ} 14$, de 1996). (BRASIL,1988)

Antes desta mudança via emenda constitucional em seu inciso I tratava exclusivamente da obrigatoriedade do ensino fundamental. O inciso II também teve sua redação alterada por outra emenda constitucional a EC n $n^{\circ} 14 / 1996$. A sua redação anterior previa a progressiva extensão da obrigatoriedade e gratuidade ao ensino médio e após emenda ficou assim: progressiva universalização do ensino médio gratuito. A retirada da palavra obrigatoriedade pode sugerir uma desobrigação do Estado em oferecê-la.

Porém foi com a criação do Fundeb que o Ensino Médio ganhou maior destaque e garantia de recursos. O Fundeb foi criado pela Emenda Constitucional no 53/2006 e regulamentado pela Lei $n^{\circ} 11.494 / 2007$ e pelo Decreto nº 6.253/2007, em substituição ao Fundo de Manutenção e Desenvolvimento do Ensino Fundamental e de Valorização do Magistério (Fundef) que vigorou de 1998 a 2006.

A LDB de 1996, modificada pela Lei n 13.415, de 2017 cita a Educação Integral associada ao Ensino Médio da seguinte forma: 
§ 7o Os currículos do ensino médio deverão considerar a formação integral do aluno, de maneira a adotar um trabalho voltado para a construção de seu projeto de vida e para sua formação nos aspectos físicos, cognitivos e socioemocionais. (BRASIL, 2017).

Em 2009, a criação do Programa Ensino Médio Inovador (PROEMI) por meio da Portaria $n^{\circ} 971$ incentiva os Estados da Federação a criarem propostas inovadoras e fornecem apoio técnico e financeiro as escolas de Ensino Médio. Este programa é o recorte de uma pesquisa maior que se encontra em andamento. Neste artigo, em especial, pretendemos relacioná-lo com as ideias de Gramsci.

No ano de 2016, através da Resolução nº 4, de 25 de outubro de 2016, o FNDE destina recursos financeiros nos moldes do Programa Dinheiro Direto na escola (PDDE) às escolas estaduais e do Distrito Federal para apoiar as propostas curriculares inovadoras conforme o Programa Ensino Médio Inovador. Essa Resolução reafirma a necessidade de atender as metas 7, 3 e 6 do Plano Nacional de Educação (PNE) 2014-2024. Entendemos que essa ordem pode significar as prioridades por parte do MEC na implantação dessa política

A necessidade de apoiar os sistemas de ensino público na operacionalização de ações voltadas à melhoria da qualidade da oferta do Ensino Médio e o Redesenho Curricular, em consonância com as Diretrizes Curriculares Nacionais para o Ensino Médio, aprovadas pelo Conselho Nacional de Educação, de forma a atender a meta 7 do Plano Nacional de Educação (PNE);

A necessidade de promover ações compartilhadas com os Estados e o Distrito Federal, para melhoria do ensino médio e a perspectiva de universalização do acesso e permanência de todos os adolescentes de 15 a 17 anos nesta etapa da educação básica, de forma a atender a meta 3 do PNE;

A necessidade de estabelecer ações conjuntas entre os entes federados, que propiciem novas organizações curriculares para o ensino médio, compatíveis com as perspectivas da sociedade contemporânea e com os anseios dos jovens e adultos, em conformidade com a Medida Provisória $n^{\circ} 746$ de 2016;

A necessidade de estabelecer políticas compartilhadas, para a ampliação dos espaços educativos no contexto das unidades escolares, que possibilitem articulações entre o mundo do trabalho, da ciência, da tecnologia e da cultura, como pressuposto à implantação gradativa da educação em tempo integral, de forma a atender a meta 6 do PNE. (BRASIL, 2016)

A Lei ${ }^{\circ} 13.415$, de 2017 modifica a LDB de 1996 e o Fundeb, induzindo a política de fomento à implementação de escolas de ensino médio em tempo integral dentre outras modificações. Destacamos o Art. 13: 
Art. 13. Fica instituída, no âmbito do Ministério da Educação, a Política de Fomento à Implementação de Escolas de Ensino Médio em Tempo Integral. Parágrafo único. A Política de Fomento de que trata o caput prevê o repasse de recursos do Ministério da Educação para os Estados e para o Distrito Federal pelo prazo de dez anos por escola, contado da data de início da implementação do ensino médio integral na respectiva escola, de acordo com termo de compromisso a ser formalizado entre as partes, que deverá conter, no mínimo:

I - identificação e delimitação das ações a serem financiadas;

II - metas quantitativas;

III - cronograma de execução físico-financeira;

IV - previsão de início e fim de execução das ações e da conclusão das etapas ou fases programadas (BRASIL, 2017).

Como apontado acima, a legislação recente é rica em relação ao Ensino Médio e mais especificamente em relação ao Ensino Médio em Tempo integral. Assim sendo, podemos perceber um avanço nas garantias legais por esse direito social e a sua importância para o MEC, como também a compreensão que a Educação Integral tem sido compreendida como estratégia para a melhoria da qualidade educacional neste segmento da educação básica.

O PNE 2014-2024 instituiu dentre suas 20 metas, duas associadas ao Ensino Médio e ao Ensino Médio em Tempo Integral.

Meta 3: universalizar, até 2016, o atendimento escolar para toda a população de 15 (quinze) a 17 (dezessete) anos e elevar, até o final do período de vigência deste PNE, a taxa líquida de matrículas no ensino médio para 85\% (oitenta e cinco por cento).

Meta 6: oferecer educação em tempo integral em, no mínimo, 50\% (cinquenta por cento) das escolas públicas, de forma a atender, pelo menos, $25 \%$ (vinte e cinco por cento) dos (as) alunos (as) da educação básica.

O PROEMI e uma das apostas por parte do governo federal para a melhoria da qualidade do Ensino médio no Brasil e vem sendo desenvolvido no estado do Rio de Janeiro desde 2009, mesmo antes da aprovação do novo PNE (2014-2024).

Como justificativa para a implantação deste Programa, o MEC expõe de maneira sintetizada aspectos essenciais da Proposta Curricular Inovadora que estão descritas no PARECER CNE/CP N. 11/2009. O MEC coloca o Ensino médio como o nível de maior complexidade na estruturação de políticas públicas, devido a sua própria natureza de caráter intermediário entre o término do Ensino Fundamental e o curso superior e por atender adolescentes, jovens e adultos com expectativas diversas em relação aos estudos neste nível. (BRASIL, 2009) 
Este incentivo diferenciado ao Ensino Médio instituído pela Portaria $N^{\circ} 971$, de 09 de outubro de 2009 já foi citado brevemente. Apontamos aqui alguns artigos dessa Portaria para entendimento do que se trata o PROEMI.

Art. $2^{\circ} \mathrm{O}$ Programa visa apoiar as Secretarias Estaduais de Educação e do Distrito Federal no desenvolvimento de ações de melhoria da qualidade do ensino médio não profissionalizante, com ênfase nos projetos pedagógicos que promovam a educação científica e humanística, a valorização da leitura, da cultura, o aprimoramento da relação teoria e prática, da utilização de novas tecnologias e o desenvolvimento de metodologias criativas e emancipadoras. Art. $3^{\circ} \mathrm{O}$ Programa Ensino Médio Inovador prestará apoio técnico e financeiro a ações de desenvolvimento e estruturação do ensino médio mediante analise, seleção e aprovação de propostas, na forma de plano de trabalho, e posterior celebração de convenio, execução direta ou descentralização de recursos, na forma da legislação aplicável.

Art. $4^{\circ}$ Poderão apresentar propostas os Estados que tenham aderido formalmente ao Plano de Metas Compromisso Todos pela Educação, de que trata o Decreto $\mathrm{N}^{\circ}$ 6.094, de 24 do abril de 2007 (BRASIL, 2009).

A Secretaria de Estado de Educação do Estado do Rio de Janeiro (SEEDUC) é participante do PROEMI. Abaixo, um trecho da proposta das escolas de Ensino Médio que fazem parte do desse Programa ${ }^{4}$.

As escolas de Nova Geração são participantes do Programa Ensino Médio Inovador - PROEMI, mas possuem uma Matriz Curricular diferenciada. Compõem um novo modelo de Escola de Ensino Médio em tempo Integral, das $7 \mathrm{~h}$ às $17 \mathrm{~h}$, com um ambiente que desenvolve as competências do jovem, suas atitudes e valores para o Século XXI. (...) Por isso, o curso de Nova Geração visa ao fortalecimento do desenvolvimento de propostas curriculares inovadoras, ampliando o tempo dos estudantes na escola e buscando garantir a formação integral com a inserção de atividades que tornem o seu currículo mais dinâmico (SEEDUC, 2015).

Cabe aqui ressaltar que a SEEDUC elaborou uma proposta inovadora para o Ensino Médio voltada aos jovens. Essa proposta é de uma escola de Educação Integral em tempo integral. E mais, afirma que a ampliação do tempo na escola visa à formação integral dos alunos. Em um dos trechos, a proposta explícita que o Programa de Educação Integral deve preparar o jovem para o convívio e a participação social e para o mundo do trabalho (SEEDUC, 2015). O que nos leva a acreditar que uma das preocupações em relação a juventude é a sua formação para o mercado de trabalho. Mas também propõe um novo olhar sobre a juventude, contemplando, assim, o desenvolvimento integral do estudante, enquanto cidadão do mundo

\footnotetext{
${ }^{4}$ Disponível em: <http://www.rj.gov.br/web/seeduc/exibeconteudo?article-id=2600834>. Acesso em: 28 set.
} 2018. 
globalizado. Em meio a algumas contradições teóricas sobre o significado de uma formação integral, voltamos o nosso olhar sobre o PROEMI e sobre o Ensino Médio Inovador desenvolvido no estado do Rio de Janeiro.

Acreditamos que o trabalho quando aliado a formação dos jovens deve ser considerado como principio educativo. Ciavatta (2009), o define assim

No caso do trabalho como princípio educativo, a afirmação remete à relação entre o trabalho e a educação, no qual se afirma o caráter formativo do trabalho e da educação como ação humanizadora por meio do desenvolvimento de todas as potencialidades do ser humano (CIAVATTA, 2009).

O Ensino Médio Inovador é uma estratégia e, também, um instrumento para induzir o redesenho dos currículos do Ensino Médio, compreendendo que as ações propostas inicialmente serão incorporadas gradativamente ao currículo, ampliando o tempo na escola, na perspectiva da educação integral e a diversidade de práticas pedagógicas de modo que estas, de fato, qualifiquem os currículos das escolas de Ensino Médio. (BRASIL, 2016 p. 3)

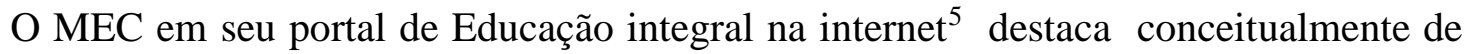
que maneira a Educação Integral foi pensada para os Programas de Educação integral.

Educação integral representa a opção por um projeto educativo integrado, em sintonia com a vida, as necessidades, possibilidades e interesses dos estudantes. Um projeto em que crianças, adolescentes e jovens são vistos como cidadãos de direitos em todas as suas dimensões. Não se trata apenas de seu desenvolvimento intelectual, mas também do físico, do cuidado com sua saúde, além do oferecimento de oportunidades para que desfrute e produza arte, conheça e valorize sua história e seu patrimônio cultural, tenha uma atitude responsável diante da natureza, aprenda a respeitar os direitos humanos e os das crianças e adolescentes, seja um cidadão criativo, empreendedor e participante, consciente de suas responsabilidades e direitos, capaz de ajudar o país e a humanidade a se tornarem cada vez mais justos e solidários, a respeitar as diferenças e a promover a convivência pacífica e fraterna entre todos.

Essa visão de Educação Integral se entrelaça com a visão de Educação Integral que embasa o Programa Ensino Médio Inovador que está voltado prioritariamente a jovens. Embora cientes das especificidades históricas que levaram Antonio Gramsci a escrever sobre a escola. E principalmente, por seus escritos voltarem sua reflexão para uma escola voltada para os proletariados, filhos da classe trabalhadora, ousamos estabelecer uma conversa crítica com as ideias de escola deste autor.

5 Disponível em: <http://educacaointegral.mec.gov.br/>. Acesso em: 23 set. 2018. 


\section{Gramsci e a Educação}

Antonio Gramsci nasceu na Sardenha, Itália no ano de 1891 e viveu por 20 anos nessa ilha atrasada, pobre e explorada. A revolta contra os ricos logo se fez presente porque não podia estudar mesmo sendo aluno nota 10 na escola elementar enquanto via os filhos dos comerciantes irem à escola. E foram suas experiências neste período que o motivaram mais tarde a se integrar nos movimentos sociais em Turim. Nosella (2016) traz um pouco do sentimento que motivou Gramsci.

Essa revolta se dilatou para todos os ricos que oprimiam os camponeses da Sardenha, e eu pensava que precisa lutar pela independência nacional da região: ao mar os continentais! Quantas vezes repeti essas palavras. Depois conheci a classe operária de uma cidade industrial e compreendi o que realmente significavam as coisas de Marx que havia lido antes por curiosidade intelectual. Me apaixonei assim pela vida, pela luta, pela classe operária (apud NOSELLA, 2016)

Trazer Gramsci para um debate atual sem contextualizar em que momento histórico ele escreveu sua obra, não seria possível. Ou pelo menos, faltariam elementos essenciais para o entendimento de suas ideias.

Salles (2012) fala de Gramsci e de questões que devem ser consideradas ao buscar nesse autor uma obra de história. A condição na qual a sua obra foi produzida em um esforço de militante e revolucionário e sob a vigilância constante do governo fascista de Mussolini. A sua maior produção se deu nos cárceres fascistas no período de 1929 a 1935. Uma obra fragmentada, lacunar e preliminar, como apontou o autor.

Fragmentado porque o escopo de seu interesse intelectual nesse período envolveu uma variedade de temas simultaneamente. E sabido que os Cadernos intercalam temas distintos, tratados como notas, muitas das quais retomadas em segundas anotações. Temas cuja conexão, mesmo quando possa ser instituída, não e dada de antemão aos leitores e possivelmente nem era evidente ao próprio Gramsci. Lacunar porque como ele mesmo apontou em carta para sua cunhada Tatiana Schucht, de 31 de agosto de 1931, faltavam-lhe as fontes necessárias para aprofundar suas observações. (BUTTIGIEG, 2011, p. 30). Finalmente, seu trabalho foi preliminar porque, consciente dessas limitações e características, consciente de que a derrota diante do fascismo representava algo mais que um contratempo passageiro e abria todo um novo período histórico, Gramsci considerava suas notas uma etapa inicial para um trabalho intelectual de maior fôlego, profundidade e alcance. (SALLES, 2012, p. 212) 
Acreditamos na importância de datar seus escritos. Nosella (2016), aponta quatro períodos a saber: $1^{\mathrm{a}}$ parte: escritos durante a primeira Guerra Mundial (1914-1916); $2^{\mathrm{a}}$ parte: Escritos do Pós-Guerra (1919-1920); 3 $3^{\text {a }}$ parte: escritos durante a ascensão do fascismo (19211926); $4^{\mathrm{a}}$ parte: Escritos do Cárcere (1926-1937). Na verdade, os cadernos começaram a ser escritos em 1929, após ter recebido autorização para estudar e escrever, no cárcere de Turim, nas imediações de Bari.

Esse último período nos interessa em particular. De acordo com Meta (2017), o tema da escola aparece nos Cadernos do Cárcere entre 1930-1932. Para Gramsci, a escola se constitui numa agência educativa complexa, materializada a partir de uma multiplicidade de estruturas sociais que se estratificam ao logo do tempo. Gramsci vai além, critica a escola humanística e de conhecimentos técnico-científicos. Descreve a multiplicação das escolas para dirigentes e especialistas. Ao lado da escola que se propunha a ensinar a cultura geral e ainda indiferenciada que ensinam a pensar e aos indivíduos a orientar-se para a vida aproximou-se um sistema de escolas particulares e diferentes níveis que se voltam a setores profissionais cada vez mais especializados.

Gramsci desde a juventude foi um crítico a especialização rígida que de acordo com a sua visão é a separação das funções intelectuais, como se o homem fosse dividido em duas partes. Também critica o saber enciclopédico desenvolvido nas universidades populares e defende a necessidade de uma educação clássica. Defende a formação a toda a humanidade, entendendo que a formação e a especialização devem se desenvolver de forma harmônica.

O proletariado precisa de uma escola desinteressada. Uma escola na qual seja dada à criança a possibilidade de ter uma formação, de tornar-se homem, de adquirir aqueles critérios gerais que servem para o desenvolvimento do caráter. Em suma, uma escola humanista, tal como a entendiam os antigos, e mais recentemente, os homens do Renascimento. Uma escola que não hipoteque o futuro da criança e não constrinja sua vontade, sua inteligência, sua consciência em formação a mover-se por um caminho cuja meta seja prefixada. Uma escola de liberdade e de livre iniciativa, não uma escola de escravidão e de orientação mecânica (GRAMSCI, 2004, p. 75).

Nosella (2016) descreve a escola Desinteressada do Trabalho que Gramsci propunha. O autor defende que o interesse de Gramsci pelas questões culturais e educativas se fundava na sua preocupação em formar os quadros dirigentes que haveriam de governar o futuro Estado Proletário. A palavra desinteressada aqui conota um sentido amplo, de longo alcance. Em uma oposição a uma educação que beneficie indivíduos ou grupos específicos, a educação deve 
beneficiar toda a coletividade. Assim sendo, podemos pensar que a escola e um espaço privilegiado de formação dos intelectuais.

Os intelectuais para Gramsci são dos tipos: os orgânicos que são mais ou menos formados no Partido e os tradicionais. Esses últimos, os professores, jornalistas, cientistas e outros que simpatizavam com o socialismo. Para Gramsci, eles eram importantes e desenvolviam importante papel na luta hegemônica, sem, contudo, mudar o seu modo de trabalhar e estudar.

A escola em uma sociedade capitalista como a brasileira pode utilizar os conceitos da escola de Gramsci?

Gramsci era um revolucionário e lutava por uma sociedade socialista onde os benefícios de classes e de dinheiro não existissem. Seus pensamentos para a educação e para a cultura em geral tinham como objetivos a revolução proletária. Sua intensa participação no partido, nos jornais, nas associações, tinha como objetivo a transformação social.

No modo de produção capitalista existe um antagonismo entre as classes que detém o poder econômico, os meios de produção e àqueles que vendem a sua força de trabalho para sobreviver. Os interesses dessas classes estão em permanente conflito. Com a educação não é diferente. Diversos grupos pleiteiam direitos sobre a educação.

Savianni (2003) lembra que existe uma grande contradição na sociedade capitalista. A ciência, como conhecimento, é incorporada ao trabalho produtivo e se transforma em meio de produção. Mas estes, na sociedade em que vivemos pertencem à classe dominante. Aí entra a contradição. Como o trabalhador pode ser expropriado do conhecimento se a própria classe dominante precisa que ele acrescente valor ao capital? Assim sendo, a sociedade capitalista desenvolveu mecanismos de fragmentação do conhecimento para passa-lo ao trabalhador de forma parcelada. Para que ele não venha obter o conhecimento total. Entendemos que assim agindo, as classes dominantes fazem ou tentam fazer da educação um dos recursos de sua dominação. Agora, o mercado precisa de um trabalhador que atenda as novas exigências. Isso inclui, necessariamente, bom raciocínio, capacidade de lidar com as novas tecnologias e a aceitação das ideias da classe dominante. A aceitação destas ideias é necessária para manter o equilíbrio na sociedade. Entramos neste momento no campo da ideologia. De acordo com Liguori (2017), Gramsci utiliza este conceito em diversos momentos de sua obra. Nos Cadernos do Cárcere, Liguori (2017) afirma que Gramsci “chega a usar o lema sobretudo com o significado de concepção do mundo de um determinado sujeito coletivo, ou mesmo individual. A ideologia identifica um grupo ou camada social.” (LIGUORI, 2017 p. 401) 
As propostas inovadoras de ensino médio podem ser vistas dentro desta ótica. Mas também podem contribuir para a construção de uma nova ideologia de classe. A importância dos intelectuais para Gramsci está posta na escola, nas fábricas, nos partidos políticos.

\section{Considerações finais}

O que resta a escola pública brasileira é lutar para que ela não se transforme em instrumento de dominação das classes que detém o poder econômico e muitas vezes, político, através da formação de intelectuais orgânicos e tradicionais da classe trabalhadora e que se identifiquem com as problemáticas de sua classe.

A portaria 971 de 2009 que instituiu o PROEMI expressa em dois objetivos dentre os dez presentes, VI e VII respectivamente, a necessidade de uma escola média que desenvolva saberes que tenham significado para os estudantes e desenvolvam sua autonomia. Neste momento do estudo, faltam elementos para afirmar que os objetivos expressos quando da criação do PROEMI se expressam no cotidiano das escolas que participam deste Programa. Mas sim que há espaço para que essa política se efetive no chão da escola de maneira a cumprilos, mesmo que parcialmente devido as condições político-históricas atuais.

Trazer os conceitos de Gramsci para a efetivação de políticas públicas na área da educação pode contribuir para a formação de uma coletividade consciente de sua condição de vida e munir os jovens com elementos para uma superação desta sociedade tão desigual.

\section{REFERÊNCIAS}

BRASIL. Constituição (1988). Constituição da República Federativa do Brasil:

promulgada em 5 de outubro de 1988. Disponível em:

http://www.planalto.gov.br/ccivil_03/constituicao/constituicao.htm. Acesso em: 10 dez. 2018.

BRASIL. Ministério de Educação e Cultura. LDB - Lei no 9394/96, de 20 de dezembro de 1996. Estabelece as diretrizes e bases da Educação Nacional. Brasília: MEC, 1996.

BRASIL. PARECER CNE/CP N. 11/2009. Proposta de experiência curricular inovadora do Ensino Médio. Ministério da Educação. 2009.

BRASIL. Ministério de Educação e Cultura. Portaria Nº 971, de 09 de outubro de 2009. Institui no âmbito do Ministério da Educação, o Programa Ensino Médio Inovador. Disponível em: http://pactoensinomedio.mec.gov.br/images/pdf/port_971_09102009.pdf. Acesso em: 23 abr. 2017. 
BRASIL. Lei $\mathbf{n}^{0}$ 13.005 de 25 de junho de 2014. Aprova o plano Nacional de Educação-PNE e dá outras providências. Disponível em: http://www.planalto.gov.br/ccivil_03/_ato20112014/2014/lei/113005.htm. Acesso em: 12 ago. 2017.

BRASIL. Resolução No 4 de 25 de outubro de 2016. Destina recursos financeiros, nos moldes operacionais e regulamentares do Programa Dinheiro Direto na escola-PDDE, a escolas públicas estaduais e do Distrito Federal, a fim de apoiar e fortalecer o desenvolvimento de propostas curriculares inovadoras, em conformidade com o Programa Ensino Médio Inovador. Diário Oficial da União, 26 de outubro de 2016.

BRASIL. Lei $\mathbf{n}^{\mathbf{0}} \mathbf{1 3 . 4 1 5}$ de 16 de fevereiro 2017. Altera as Leis nos 9.394, de 20 de dezembro de 1996, que estabelece as diretrizes e bases da educação nacional, e 11.494, de 20 de junho 2007, que regulamenta o Fundo de Manutenção e Desenvolvimento da Educação Básica e de Valorização dos Profissionais da Educação, a Consolidação das Leis do Trabalho - CLT, aprovada pelo Decreto-Lei no 5.452, de 1o de maio de 1943, e o Decreto-Lei no 236, de 28 de fevereiro de 1967; revoga a Lei no11. 161, de 5 de agosto de 2005; e institui a Política de Fomento à Implementação de Escolas de Ensino Médio em Tempo Integral. Disponível em: http://www.planalto.gov.br/ccivil_03/_ato2015-2018/2017/lei/L13415.htm. Acesso em: 12 ago. 2017.

CIAVATTA, Maria. Trabalho como princípio educativo. Dicionário da educação profissional em saúde. Fundação Oswaldo Cruz. Escola Politécnica Joaquim Venâncio. Rio de Janeiro, 2009. Disponível em: sites.espsjv.fiocruz.br. Acesso em: 01 jul. 2018.

FRIGOTTO, Gaudêncio.; MOTTA, Vânia. Por que a urgência da Reforma do Ensino Médio? Medida provisória No 746/2016(Lei No 13.415/2017). Educação e Sociedade, Campinas, v. 38, n. 139, p. 355-372, abr./jun., 2017.

GRAMSCI, Antonio. Escritos Políticos, v. 1, Rio de Janeiro: Civilização Brasileira, 2004.

HÖFLING, Eloisa de Mattos. Estado e políticas (públicas) sociais. Cadernos Cedes, Ano XXI, n. 55, nov., 2001. Disponível em: http://www.scielo.br/scielo.

php?script=sci_arttext\&pid=S0101-32622001000300003. Acesso em: 12 ago. 2017.

LIGUORI, Guido.; PASQUALE Voza. Orgs. Dicionário Gramsciano (1926-1937)

Tradução: Ana Maria Chiarini; Diego Silveira Coelho Ferreira, Leandro de Oliveira Galastri e Silvia de Bernadini. 1. ed. São Paulo: boitempo, 2017.

LIGUORI, Guido. Ideologia, Dicionário Gramsciano (1926-1937). Tradução: Ana Maria Chiarini; Diego Silveira Coelho Ferreira, Leandro de Oliveira Galastri e Silvia de Bernadini. 1. ed. São Paulo: boitempo, 2017.

META, Chiara. Escola, Dicionário Gramsciano (1926-1937). Tradução: Ana Maria Chiarini; Diego Silveira Coelho Ferreira, Leandro de Oliveira Galastri e Silvia de Bernadini. 1. ed. São Paulo: boitempo, 2017.

NOSELLA, Paolo. A Escola de Gramsci. 5. ed. Ampl. São Paulo: Cortez, 2016. 
SALLES, Ricardo. Gramsci para historiadores. História da historiografia, Ouro preto, n. 10, dez., p. 211-228, 2012.

SAVIANI, Dermeval. O choque teórico da politecnia. Trabalho, Educação e Saúde, Rio de Janeiro: EPSJV, v. 1, n. 1, 2003.

SAVIANI, Dermeval. A Lei da Educação: LDB, trajetória, limites e perspectivas. 13. ed. Ver. Atual., e ampl. Campinas-São Paulo: Autores associados, 2016.

\section{Como referenciar este artigo}

SILVA, Flávia Gonçalves.; BERNADO, Elisangela da Silva. Ensino médio em tempo integral e a escola de Antonio Gramsci: é possível utilizar os conceitos de Gramsci no desenvolvimento de uma escola de ensino médio mais igualitária?. Revista on line de Política e Gestão Educacional, Araraquara, v. 23, n. 1, p. 160-174, jan./abr., 2019. E-ISSN: 1519-9029. DOI: 10.22633/rpge.v23i1.11818

Submetido em: 12/10/2018

Revisões requeridas: $15 / 11 / 2018$

Aprovado em: 10/12/2018

Publicado em: 02/01/2019 